\title{
O PROCESSO DE ADAPTAÇÃO DAS CRIANÇAS À CRECHE SOBRE O PRISMA DAS FAMÍLIAS USUÁRIAS.
}

\author{
Suélen Cristiane Marcos, Gilza Maria ZauhyGarms.
}

Universidade Estadual Paulista Júlio Mesquita Filho - UNESP, Programa de Pós Graduação em Educação, Presidente Prudente, SP. E-mail: ssucris@hotmail.com. CAPES.

\begin{abstract}
RESUMO
Este trabalho é fruto de um recorte de uma pesquisa de doutorado em andamento e tem por objetivo identificar as concepções, sentimentos e sugestões das famílias a respeito do processo de adaptação das crianças às instituições de Educação Infantil. A pesquisa enquadra-se numa abordagem qualitativa, discutindo o ingresso das crianças às creches e o papel dos profissionais e das famílias neste contexto. O campo de investigação foi uma instituição, pública de Presidente Prudente, que atende 182 crianças de 4,5 meses a 3 anos. Os procedimentos de coleta de dados foram entrevistas semi-estruturadas dirigidas a 30 famílias. Quanto às concepções das famílias a respeito da adaptação das suas crianças verificou-se que estão fortemente relacionadas às reações infantis a esse processo, considerando que as crianças que demonstraram um grande sofrimento ou adoecimento, manifestaram doenças, choro intenso, relutância em dormir como difíceis de adaptarem á creche.
\end{abstract}

Palavras-chave: adaptação, creche, família, crianças, prática docente.

\section{THE CHILDREN'S ADAPTATION PROCESS THE CRECHE ON THE PRISM OF USER FAMILIES.}

\begin{abstract}
This work is the result of a review of a doctoral research in progress, and aims to identify the conceptions, feelings and suggestions of the families regarding the process of adaptation of the children to the institutions of Early Childhood Education. The research is framed in a qualitative approach, discussing the children's entry to day-care centers and the role of professionals and families in this context. The field of investigation was a public institution of Presidente Prudente, which serves 182 children from 4.5 months to 3 years. The data collection procedures were semistructured interviews directed to 30 families. Regarding the conceptions of the families regarding the adaptation of their children, it was verified that they are strongly related to the children's reactions to this process, considering that children who showed great suffering or illness, manifested illness, intense crying, reluctance to sleep as difficult to Adapting to day care.
\end{abstract}

Keywords: adaptation, nursery, family, children, teaching practice. 


\section{INTRODUÇÃO}

Este artigo é fruto de um recorte de uma pesquisa de doutorado em andamento intitulada "O processo de adaptação das crianças na Educação Infantil: os desafios das famílias e dos educadores da infância".

Atualmente, as crianças adentram o espaço das instituições para a infância cada vez mais cedo, por volta dos 3 meses de idade, quando ainda apresentam uma grande dependência de adultos responsáveis para atender as suas necessidades. Assim fez-se necessário que a Educação Infantil melhorasse em qualidade e fosse redefinida como um direito da criança, a primeira etapa da educação básica e responsável por complementar a ação educativa das famílias, cuidar e educar as crianças e desenvolver todas as potencialidades infantis como reforçam a legislação e documentos oficiais dirigidos a Educação Infantil LDB (BRASIL, 1996), Diretrizes Curriculares Nacionais para Educação Infantil (BRASIL, 2009), Referenciais Curriculares para Educação Infantil (BRASIL, 1998), A Constituição Federal de 1988 (BRASIL, 1998).

Quando a criança ingressa pela primeira vez na creche, o faz num mundo diferente do até então conhecido familiar, terá que se relacionar obrigatoriamente com novos cuidadores, se adaptar ao um novo espaço e rotinas da instituição o que pode ocasionar ansiedades, angústias, tanto para as crianças como as suas famílias. As reações infantis podem se manifestar como físicas, dores, febres, vômitos, diarreia, entre outros sintomas ou emocionais, não dormir, não aceitar alimentação, não brincar, timidez, apatia, raiva, agressividade (RAPOPORT; PICCININI, 2001). Já os sentimentos das famílias variam entre alívio por conseguir uma vaga para suas crianças e poderem, principalmente, participarem do mercado de trabalho, entre culpa, sensação de abandono das crianças, inseguranças com relação aos cuidados oferecidos pela criança na instituição, que deixam de ser individualizados em casa para o cuidado coletivo das instituições (MARANHÃO E SARTI, 2008).

Por ser a experiência de adaptação emocionalmente exigente para as crianças e as famílias sendo que algumas não conseguem se adaptar à instituição faz-se necessário aprofundar os estudos sobre esse processo que possibilitem a instituição se preparar para recepcionar a criança e a família, oferecendo segurança aos mesmos frente ao desconhecido contribuindo para a construção de uma noção de familiaridade com a instituição de Educação Infantil.

Esse estudo defende que o processo de adaptação implica no envolvimento das famílias, pois, a criança precisa do apoio familiar para conseguir se tornar um membro pertencente da instituição, sendo os familiares mediadores na apresentação do novo espaço, pessoas e rotina, são as reações das famílias que ressignificam essa experiência infantil. (BRASIL, 1998); (ROSSETTI FERREIRA; AMORIM \& VITÓRIA, 1994).

É um processo que se inicia no momento em que as famílias vão realizar a matricula dos filhos e deve se consolidar em uma parceria duradoura por todo o tempo em que a criança permanecer na instituição visando minimizar o sofrimento e traumas infantis frente ao processo de inserção e promoção do desenvolvimento, aprendizagem e bem estar infantil.

Por acreditarmos que o processo de adaptação das crianças deva ser um elo entre as instituições de Educação Infantil e as famílias, julgamos imprescindível que tanto os profissionais como as famílias, conheçam o seu papel e entendam a importância de sua atuação. O processo de adaptação das crianças à creche muitas vezes tem sido caracterizado pela angústia das crianças e suas famílias, em decorrência da ausência da parceria real entre as instituições de Educação Infantil e as famílias. Sendo comuns situações de separação abrupta das crianças de suas famílias, sendo conduzidas chorando para dentro das instituições de Educação Infantil pelos profissionais e a impotência das famílias perante as orientações dos profissionais que o melhor para a criança é que os familiares a deixem na instituição aos cuidados dos mesmos.

Parece existir consenso entre os profissionais que em algum momento as crianças vão parar de reagirem ao processo de adaptação, principalmente por meio de choro, reação que mais 
desencadeia inseguranças nos familiares, por acabaram se acostumando ou sendo vencidas pelo esgotamento físico ou emocional.

Neste sentido, esta pesquisa surge da necessidade de propor alternativas para o ingresso das crianças à creche, que se traduz por meio do objetivo geral de discutir o processo de adaptação das crianças às creches e o papel dos profissionais e das famílias neste contexto. Para além dele, a pesquisa possui como objetivos específicos identificar as concepções, sentimentos das famílias a respeito do processo de adaptação das crianças às instituições de Educação Infantil e averiguar quais são as estratégias de adaptação utilizadas pelos profissionais da Educação Infantil e se existe neste processo a parceria com as famílias.

\section{METODOLOGIA}

A pesquisa, foi aprovada pelo comitê de ética e pesquisa da FCT-UNESP, como consta o protocolo CAAE 52850316.7.0000.5402, é de natureza qualitativa, pois possibilita responder inquietações particulares, elucidando uma realidade complexa e contextualizada que não pode ser quantificada (MINAYO, 1993).

O campo de investigação foi uma instituição de Educação Infantil de uma cidade do interior do Estado de São Paulo (SP), pública, que atende 182 crianças, de 4,5 meses a 3 anos e como sujeitos os profissionais que atuam na instituição, 7 professores, 11 educadores e 30 famílias usuárias, cujos filhos, passam pelo processo de adaptação as creche.

A técnica empregada para recolha de dados foram entrevistas semi-estruturadas, dirigidas aos educadores, professores e as famílias para identificar e avaliar suas concepções a respeito da adaptação das crianças à creche e para que explicitem suas expectativas sobre o papel que desempenham nesse processo.

Neste trabalho especificamente buscamos identificar e discutir as concepções das famílias a respeito da adaptação infantil à creche, priorizando os casos consideráveis difíceis, para isso nos focamos na análise parcial das repostas oferecidas por 6 membros familiares usuários da instituição participante.

\section{RESULTADOS}

Considerando a teoria da rede de significações (Amorim; Vitória; Rossetti-Ferreira, 2000) na qual essa pesquisa se baseia ao analisar as concepções das famílias é preciso considerar o cenário da família, que é marcado pela história de vida de seus membros e pelo momento vivido na atualidade, assim como pelas influências étnicas, culturais e sociais, possibilitando experiências e interações diferentes entre eles.

Assim as famílias quando solicitadas a definirem o processo de adaptação de suas crianças o fazem com base principalmente nas reações que as mesmas apresentaram, algumas crianças foram consideradas como difíceis de adaptarem à creche, como exemplifica a fala da mãe 1 que justifica que o processo de adaptação foi mais penoso para a segunda filha porque a mesma possuía vínculos afetivos bem estreitos, apenas com a mãe e o pai.

A minha segunda filha foi um pouco mais difícil, porque ela demorou um pouco mais para se adaptar foi um mês, mais o menos, ela chorava muito [...] mas porque ela era muito grudada na gente, dentro de casa já era assim, não ia com pessoas que não fosse do convívio dela, até mesmo quem era muito próximo, tia, tio, bisavó não conseguia pegar ela ou era os pais, meu marido, ou era minha mãe e meu pai, ela não ia com muita gente. (MÃE 1). 
A mãe 14 e 23, assim como a mãe 1, também acreditam que as dificuldades que as filhas apresentaram para se adaptar à creche se devem ao fato das mesmas serem muito apegadas a elas.

Ela foi bem ela ficou um mês em adaptação, ficando só umas duas horas na creche, porque ela ficava mais comigo ela não se adaptou muito com as crianças, mas é normal. Ela mordia as crianças, batia, não queria ficar lá, ela não comia era difícil. Chorou um mês, a escola mandava buscar no máximo com três horas. (MÃE 14).

Foi muito difícil porque ela tinha um apego muito afetivo comigo, por ser primeiro filho, ter todo esse carinho todo né? E como ela não tem o pai presente porque eu sou mãe solteira o apego é dobrado, então pra ela ir pra creche foi uma luta, eu cuido dela sozinha, tenho o apoio do meu pai e da minha mãe. (MÃE 23)

Já a mãe 23 acredita que as dificuldades da filha na adaptação à creche se devem ao fato dela ser mãe solteira, ter se casado novamente e mudado da casa dos pais nesse período. A mãe considera que a entrada da filha na creche, o relacionamento com novas pessoas a ajudaria a lidar com essas difíceis transformações familiares.

Ai eu coloquei ela na creche porque eu me casei de novo, com um novo marido e eu acho que ela tem a necessidade de interagir com outras pessoas, eu mudei de casa, ela era uma criança que ficava muito só.

Meu marido trabalha fora eu fico em casa muito sozinha com ela, ela sente muita falta dos meus pais, dos avós que estavam sempre com ela.

E eu senti essa necessidade de colocar ela na creche pra ela ter contato com outras crianças, contato com outros ambientes, mas para que ela pudesse distrair um pouco né? A cabecinha dela, ter outras coisas pra fazer. (MÃE 23)

O pai 18 diz que o filho, de um ano, deu trabalho para se adaptar a creche, exigindo uma maior atenção da família para levá-lo e buscá-lo, e depois de um tempo demonstrou ter se acostumado com a instituição, entretanto, no momento da conversa com a pesquisadora, o pai relatou que o filho não estava mais querendo ir à creche, o pai acredita que o fator mais significativo que desencadeou essa regressão na adaptação do filho foi ele ter passado a ficar o período integral na creche e não mais meio período.

É no começo ele chorou, muitas vezes, a gente teve que ir junto acompanhando ele até a entrada da creche e ir buscando ele mais cedo para ele se adaptar a creche né?

E ai depois ele foi se acostumando, agora depois de um tempo ele não quer ir mais para a escola, mas tem que ir né? Pra aprender, acho que não sei se tem algo aqui que ele não tá gostando ele chora muito e esperneia não quer ir à creche, mas a gente tá sempre incentivando ele pelo futuro dele né? Não é só pra nós é bom pra ele também né?

Hoje ele chora pra ele não ir, teve um tempo que ele foi, agora tá chorando e a gente tá incentivando ele né? É porque antes ele não ficava o dia todo e agora ele tá ficando não sei se ele tá estranhando esse hábito né?(PAI 18).

A tia 4 também esclarece que a adaptação do sobrinho à creche foi bem difícil, durando dois meses em decorrência de ele apresentar choro intenso, vômito, e recusa a se alimentar e a 
dormir na creche, a tia 4 atribui essa reação à troca de professoras vivenciado pelo sobrinho, já que ele havia se adaptado com a primeira professora e com a troca regrediu.

Foi bem difícil nós quase tiramos porque ele chorou muito, principalmente da transição de uma professora para a outra, mudou de professora, ele se adaptou muito bem com a primeira professora mandava beijo pra ela, mexia com ela e agora que ele parou de chorar com a outra professora, ele não queria ficar na escola.

Ele chorou desde início da aula até duas semanas atrás (cerca de dois meses), tinha dia que eu vinha buscar elas falavam que ele vomitou de tanto que chorou, ele não dormia, não queria comer, agora ele tá vindo, ele brinca, ele gosta de vir porque ele vinha chorando desde a casa dele, dois meses depois ele tá ótimo. (TIA 4).

Já a mãe 19 atribui as dificuldades de adaptação do filho de três anos à creche a incapacidade da professora em se relacionar com ele e a respeitar a sua timidez:

Foi bem tranqüila, no início foi bem tranqüila, com relação à entrada, com os amiguinhos...

O problema dele mesmo foi dentro da sala de aula, porque ele era muito tímido, tinha vergonha, ás vezes até de falar e a professora não teve sabedoria, onde teve um bloqueio, na minha frente ela tratava ele super bem, mas quando chegava em casa ele não queria ir na escola, e eu achava que era por causa da escola.

Eu saia da minha casa longe pra deixar ele aqui porque falavam que era uma escola melhor, mas eu enfrentei muitas barreiras com essa questão de adaptação.

Como ele tinha problema de fala, às vezes ele trocava as palavras, ela era muito bruta com ele, ele fica com vergonha, se chamar atenção dele no meio dos outros ele morre, então isso houve um bloqueio muito grande, ele não chorava, mas era muito quieto, para se adaptar com a professora na sala de aula foi difícil. (MÃE 19).

A mãe 23 , assim como a mãe 19 , atribui o não desejo da filha de freqüentar a creche a falhas na prática pedagógica, na incapacidade docente de acolher adequadamente sua filha e as demais crianças.

Mas quando ela entrou na creche foi muito difícil ela ia chorando e voltava chorando, chorava aqui o tempo todo, quando eu deixava ela, ela ficava chorando ai a professora recebia ela, acalmava ela e ela não chorava no decorrer do tempo que ficava na creche.

Mas quando eu ia buscar ela já vinha com os olhinhos cheios de lágrimas, ela ficou assim uns cinco meses, até que um dia eu resolvi conversar com ela "bebê porque é que você chora quando a mamãe deixa você na creche qual o motivo?" e ela não respondia e eu sempre insistindo até que um dia ela disse "- mamãe eu não gosto da minha professora" ai eu falei porque ela não é boazinha com você, ela balançou a cabeça que não [...]

Ai o que eu fiz eu fiquei lá de fora, escutando como ela era com as crianças e realmente ela se mostrou ser uma professora muito bruta, vamos usar esse termo, ela não tinha aquele tato, aquela paciência, aquela delicadeza com as crianças dentro da sala, às vezes eu chegava e até escutava algumas 
crianças chorando, até ai eu achava que era pelo comportamento dela que as crianças não tinham aquele apego com ela. (MÃE 23).

Somente quando a troca de professora foi realizada a criança se adaptou à creche e parou de chorar.

\section{DISCUSSÃO}

As famílias além de se basearem nas reações infantis para descreverem o processo de adaptação infantil à creche, é evidente que entendem o mesmo como sendo um período em que as crianças devem ficar poucas horas na creche para se acostumarem ao novo ambiente, à rotina e as novas pessoas que passaram a cuidar delas para o bem da criança, acreditamos que por influência das concepções das profissionais.

Neste novo caminho que se enfrentará é importante que a criança identifique o ambiente. De fato, para que o primeiro dia se torne motivo de sorrisos em vez de lágrimas, a maioria dos especialistas aconselha estadas mais curtas no início. "A entrada no Jardim de Infância deve ser feita aos poucos". "No princípio, apenas algumas horas e só depois o dia todo", defende a psicóloga (Helena Marujo, apud Aranha, [2015]).

A sensibilidade da mãe 23 perante as dificuldades familiares vivenciadas pela filha está em consonância com as descobertas de Castoldi, Lopes e Prati, (2005) de que a ocorrência de eventos estressores, imprevisíveis na família, com perdas reforçadas pela carência de vínculos de proximidade afetiva são comuns nas crianças com dificuldades de adaptação à pré-escola.

O pensamento de Rapoport (2005, p. 19) nos leva a refletir sobre as concepções maternas a respeito das críticas às ações pedagógicas das professoras de seus filhos, pelo fato da autora considerar o trabalho docente sensível às necessidades da criança imprescindível para o sucesso da adaptação infantil, principalmente no caso de bebês.

A ação pedagógica das educadoras pode ser considerada um dos fatores mais relevantes em termos da adaptação dos bebês à creche. A qualidade dos cuidados depende em grande parte da habilidade de as profissionais prestarem atenção em cada um e levarem em conta as reações individuais dos bebês.

Acreditamos que o pai 18 e a tia 4 têm razão ao afirmarem que a mudança no tempo de permanência da criança à creche e a troca de professoras desencadeou comportamentos regressivos nas crianças que por sua vez são evidencias de problemas na adaptação (RAPOPORT; PICCININI, 2001). Rapoport (2001) em sua pesquisa sobre o ingresso de bebês e crianças pequenas a creche apontou com um fator estressante para a criança que vivencia a adaptação a duração da separação dos pais e troca de educadoras ou professoras que dificulta a formação de um vínculo entre a profissional e criança.

Concordamos com a mãe 19 que acredita que a professora pode cometer erros ao tentar ajudar as crianças mais tímidas, colocando-as no centro da atenção, impondo, chamando o olhar de todo o grupo para ela, convocando-a a participar, acreditando que assim conseguirá garantir a sua interação, o que, em algumas situações, pode intensificar sua timidez. É importante encontrar meios de inserir a criança tímida nas atividades escolares, respeitando seu tempo e o direito de ser reservada. 


\section{CONCLUSÃO}

Por meio das concepções familiares é notável que as famílias compreendem o processo de adaptação das crianças à instituição de Educação Infantil com base nas reações apresentadas pelas mesmas e nas avaliações da criança por parte das profissionais, sendo ambos os fatores determinantes para se definir a criança fácil de adaptar e aquela que demorou a se adaptar.

As crianças consideradas mais difíceis de adaptarem a creche de acordo com os responsáveis apresentaram reações de enfrentamento, tais como, choro, tanto nos primeiros dias como por meses, doenças, recusam a se alimentar ou a ficar na creche. As famílias atribuíram tais dificuldades infantis ao apego exagerado das crianças aos pais, ao estranhamento por parte das crianças ao novo ambiente, as crianças e profissionais e a incapacidade docente de acolher adequadamente a criança o que elucida "que as famílias têm a percepção de que existe uma diferenciação entre os vínculos familiares e os com outras pessoas no ambiente escolar, sendo que os de família são os primeiros que a criança vivencia e cria". (GONÇALVES; DAMKE, 2016, p. 3383).

\section{REFERÊNCIAS}

AMORIM, K. DE S; VITÓRIA, T; ROSSETTI-FERREIRA, M, C. Rede de significações: perspectiva para análise da inserção de bebês na creche. Cadernos de Pesquisa, n. 109, p. 115-144, mar./2000.

ARANHA, Adriana. Adaptação - Depoimentos de um pai. Disponível em: <http//: www.adaptacao/depoimentosdeumpai.htm>. Acesso em: 21 set. 2015.

BRASIL. Constituição (1988). Constituição da República Federativa do Brasil: promulgada em 5 de outubro de 1988. Organização do texto por Juarez de Oliveira. 4. ed. São Paulo: Saraiva, 1990. 168 p. (Série Legislação Brasileira).

BRASIL, Resolução CEB n.5 de 17 de Dezembro de 2009. Fixa as Diretrizes Curriculares Nacionais para a Educação Infantil. Brasília: MEC/Secretaria.

BRASIL. Série mesa educadora para a primeira infância. Vol.3 Brasília: MEC/UNESCO, 2011, p. 194.

BRASIL. Lei de Diretrizes e Bases da Educação Nacional. Lei no. 4.024, de 20 de dezembro de 1961.

BRASIL. Ministério da Educação e do Desporto. Secretaria de Educação Fundamental. Referencial curricular nacional para a educação infantil. Brasília: MEC/SEF, 1998. v.1.

CASTOLDI, L; LOPES, R de C. S; PRATI, L. E. O Genograma como Instrumento de Pesquisa do Impacto de Eventos Estressores na Transição Família-Escola. Revista Psicologia: Reflexão e Crítica, vol. 19, n.2, 2005. p. 292-300.

GONÇALVES, J.P.; DAMKE, A.S. O processo de adaptação: os primeiros dias da criança no ambiente escolar. Disponível em: http://www.pucpr.br/eventos/educer. Acessado em fevereiro de 2016.

MARANHÃO, D.G.; SARTI, C.A. Creche e família: uma parceria necessária. Cadernos de Pesquisa, v. 38, n. 133, jan./abr. 2008, p. 171-194, https://doi.org/10.1590/S0100-15742008000100008.

MINAYO, M.C. S. Pesquisa social: teoria, métodos e criatividade. 21 ed. Petrópolis: Vozes, 1993. 
RAPPAPORT, Andrea e PICCININI, Cesar Augusto. $\mathbf{O}$ ingresso e adaptação de bebês e crianças pequenas à creche: alguns aspectos críticos. Psicologia: reflexão e crítica, 2001, v.14. n.1, p. 8195. Acesso em fevereiro de 2016. Disponível em: http://www.lume.ufrgs.br.

RAPOPORT, Andrea. Adaptação de bebês à creche: a importância da atenção de pais e educadores. Porto Alegre: Mediação, 2005.

ROSSETTI-FERREIRA, Clotilde; VITÓRIA, Telma. Processo de Adaptação na creche. Cadernos de Pesquisa. São Paulo, no. 86, p.55-64, ago. 1994. 